\title{
Does the Change in the Indications of Endoscopic Sinonasal Surgery Continue? Data between 1994-2018
}

\author{
Original Investigation $>$ Mehmet Fatih Karakuş $^{1}\left(\mathbb{D}\right.$, Kürşat Murat Özcan $^{1}$ (D), Müge Özcan ${ }^{1}$ (D), Süleyman Emre Karakurt ${ }^{1}$ (D), \\ Mehmet Ali Çetin ${ }^{1}$ (D), Mustafa Çolak ${ }^{1}$ (D), Fakih Cihat Eravc1 ${ }^{1}$ (D), Yeşim Yüksel² (D), Ali Titiz ${ }^{3}$ (D), \\ Adnan Ünal ${ }^{1}$ \\ ${ }^{1}$ Department of Otorhinolaryngology, University of Health Sciences Ankara Numune Training and Research Hospital, Ankara, Turkey \\ ${ }^{2}$ Department of Otorhinolaryngology, University of Health Sciences Antalya Training and Research Hospital, Antalya, Turkey \\ ${ }^{3}$ Clinic of Otorhinolaryngology, Acıbadem Ankara Hospital, Ankara, Turkey
}

Abstract

ORCID IDs of the authors: M.F.K. 0000-0002-6264-5416; K.M. $0.0000-0002-5262-0565$ M. $0.0000-0003-2384-3564$; S.E.K. 0000-0002-3394-8119; M.A.C.. 0000-0003-0479-7304; M.C. 0000-0002-3191-4134; F.C.E. 0000-0001-9092-7923; Y.Y. 0000-0003-2280-3843; A.T. 0000-0002-8038-0781; A.Ü. 0000-0003-4015-0727.

Cite this article as: Karakus MF, Özcan KM Özcan M, Karakurt SE, Çetin MA, Çolak M, et al. Does the Change in the Indications of Endoscopic Sinonasal Surgery Continue? Data between 1994-2018. Turk Arch Otorhinolaryngol 2020; 58(1): 5-9.

Corresponding Author:

Mehmet Fatih Karakuş, mfkarakus@yahoo.com

Received Date: 02.10 .2019

Accepted Date: 30.11.2019

Content of this journal is licensed under a Creative Commons Attribution 4.0 International License. Available online at www.turkarchotolaryngol.net
Objective: Endoscopic sinonasal surgery (ESS) has changing over the years in parallel with the developments in endoscopy devices, video-imaging techniques, and surgical instruments. In the present study we investigated whether the indications of patients who underwent surgery over a period of 25 years have accommodated to these changes.

Methods: We retrospectively evaluated 1173 patients who underwent surgery in our clinic from 1994 through 2007, and 954 patients who underwent surgery from 2008 through 2018. The patients were divided into three groups as follows: chronic rhinosinusitis with polyps (CRSwNP), chronic rhinosinusitis without polyps (CRSsNP), and others. The changes in the indications during the first 14 years and the fol- lowing 11 years were compared, and the results were statistically evaluated.

Results: A significant decrease was observed in the number of patients who underwent surgery following the diagnosis of CRSsNP $(p<0.001)$. In addition, a statistically significant increase was found in CRSwNP $(p<0.001)$ and other $(p<0.001)$ indications.

Conclusion: When ESS indications identified in our clinic were reviewed, it was observed that the increasing trend in CRSwNP rate in the first 14 years continued, there was a significant increase in non-CRS indications in the last 11 years, and there has been an increase in patients with fungal sinusitis, especially in this group.

Keywords: Sinusitis, nasal polyps, nasal surgical procedures, endoscopy, chronic disease

\section{Introduction}

The first endoscope usage in 1970s by Messerklinger (1), following Kennedy et al. (2) and Stammberger (3) in the 1980s made a revolution in the diagnosis and treatment of sinonasal diseases. The widespread use of nasal endoscopy has allowed for the diagnosis of pathologies in narrow nasal cavities and recesses of the nose and enabled the treatment of the disease followed by a rapid healing process while protecting nasal functions and resulting in a significant increase in patient comfort (4).

Endoscopic sinonasal surgery (ESS) has continued to change in parallel with the development of endoscopes, video-imaging techniques, and surgical instruments. Interventions can be successfully performed today for the pathologies of anatomical regions that were previously deemed inaccessible.
Consequently, the indications for the patients who undergo surgery have changed over the years. We have previously reviewed these indications over a period of 14 years and reported changes (5).

The aim of the present study was to evaluate the status of the change in the past 11 years and answer the following questions regarding the changes witnessed over a period of 25 years: "What are the indications of ESS?" and "Does the change in indications continue?"

\section{Methods}

In the present study, 954 patients who underwent ESS from January 2008 through December 2018 at an otorhinolaryngology clinic were retrospectively evaluated. These patients were discussed with patients who underwent surgery in our clinic from 1994 through 2007, including the cases 
that were previously published (5). Presurgical paranasal sinus computed tomography (PNSCT) and intranasal endoscopic examination records were reviewed. The study was approved by University of Health Sciences Ankara Numune Training and Research Hospital Clinical Research Ethics Committee (Number: E-19-2638, March 28, 2019), and it was conducted in line with the ethical principles described by the Declaration of Helsinki. Informed consent was preoperatively obtained from all participating subjects. In cases where there was a discrepancy between presurgical diagnosis and intrasurgical diagnosis, the intrasurgical diagnosis was considered for evaluation and the records were transferred in this way. Cases where patients were treated using methods combined with an external approach and where surgery was performed due to recurrence were excluded from this study. Patients were divided into the following three groups according to the revised European Position Paper on Rhinosinusitis and Nasal Polyps (EPOS) 2012 (6) criteria: chronic rhinosinusitis with polyps (CRSwNP), chronic rhinosinusitis without polyps (CRSsNP), and others.

PNSCT examinations were performed using Aquilion 64 computed tomography (CT) Scanner (Toshiba Medical Systems, Japan). CT parameters were $120 \mathrm{kVp}, 100-150 \mathrm{~mA}, 1 \mathrm{~mm}$ adjacent slice thickness, $512 \times 512$ matrix size, and field of view. The surgeries were performed using 0 - and 30-degree rigid telescopes with Olympus video endoscopy systems (Olympus Medical Systems, Japan).

All patients underwent surgery under general anesthesia. In patients with CRSwNP and CRSsNP, the surgery was performed using the Messerklinger technique. Microdebrider-guided surgery was performed in patients with nasal polyps. According to the existing pathology of the patient, uncinectomy, middle meatal antrostomy, anterior ethmoidectomy, posterior ethmoidectomy, sphenoidotomy, and frontal sinus approach were used either separately or in combination. In patients with concha bullosa, the lateral lamella of the middle concha was partially excised and the attachment site of the concha posterior was preserved. Surgical micro-drill was used as an assistive instrument for endonasal tumor surgery and in patients with choanal atresia and osteoma and in some patients with rhinolith.

Patients who underwent ESS in the last 11 years were compared with those who underwent surgery from 1994 through 2007 and the changes in indications for CRSwNP, CRSsNP, and other indications over the years were statistically evaluated.

\section{Statistical Analysis}

Categorical data were expressed as number and percentage. Categorical data were assessed using the Chi-square or the Fisher's exact tests. IBM Statistical Package for the Social Sciences software for Windows version 21.0 (IBM SPSS Corp.; Armonk, NY, USA) was used for all statistical calculations.

\section{Results}

Of the 954 patients included in the present study, 491 (51.4\%) were female and $463(48.6 \%)$ were male, and their ages ranged from one to 67 years (mean \pm standard deviation $37.14 \pm 13.19$ ).
Table 1 shows the yearly distribution of patients who underwent surgery in the last 11 years, from 2008 through 2018. ESS indications from 2008 through 2018 are given in Table 2.

When we compared the indications in the years 1994 through 2007 with the indications in the last 11 years from 2008 through 2018 , we found that the number of patients who underwent surgery following the diagnosis of CRSsNP had significantly decreased $(\mathrm{p}<0.001)$. In addition, a statistically significant increase was noted in CRSwNP $(\mathrm{p}<0.001)$ and in other $(\mathrm{p}<0.001)$ indications (Table 3, 4 and Figure 1).

Of the 79 patients who underwent surgery with the indication of nasal/paranasal sinus tumor, 47 had inverted papilloma, 11 had exophytic papilloma, nine had angiofibroma, six had pyogenic granuloma, two had schwannoma, two had pleomorphic adenoma, and two had angiomyolipoma.

Table 1. Distribution of patients undergoing surgery in the last 11 years

\begin{tabular}{l|c|c|c|c}
\hline Years & $\mathbf{N}$ & CRSwNP & CRSsNP & Other \\
\hline 2018 & 53 & 23 & 13 & 17 \\
\hline 2017 & 57 & 26 & 12 & 19 \\
\hline 2016 & 59 & 29 & 16 & 14 \\
\hline 2015 & 79 & 38 & 20 & 21 \\
\hline 2014 & 80 & 38 & 19 & 23 \\
\hline 2013 & 87 & 47 & 16 & 24 \\
\hline 2012 & 86 & 40 & 16 & 30 \\
\hline 2011 & 105 & 61 & 28 & 16 \\
\hline 2010 & 113 & 62 & 24 & 27 \\
\hline 2009 & 121 & 60 & 29 & 32 \\
\hline 2008 & 114 & 64 & 26 & 24 \\
\hline Total & 954 & 488 & 219 & 247 \\
\hline
\end{tabular}

N: Number of patients; CRSwNP: Chronic Rhinosinusitis with polyps; CRSsNP: Chronic Rhinosinusitis without polyps

Table 2. Indications for endoscopic sinonasal surgery in our institution from 2008 through 2018

\begin{tabular}{l|c|c}
\hline Indication & $\mathbf{N}=\mathbf{9 5 4}$ & Ratio (\%) \\
\hline CRSwNP & 488 & 51.1 \\
\hline CRSsNP & 219 & 22.9 \\
\hline Concha Bullosa & 57 & 5.9 \\
\hline Nasal/paranasal sinus tumour & 79 & 8.2 \\
\hline Rhinolith/foreign body & 27 & 2.8 \\
\hline Mucocele & 19 & 1.9 \\
\hline Choanal atresia & 9 & 0.9 \\
\hline Fungal sinusitis & 34 & 3.5 \\
\hline Cerebrospinal fluid leak repair & 4 & 0.4 \\
\hline Osteoma & 11 & 1.1 \\
\hline Septal perforation repair & 7 & 0.7
\end{tabular}

N: Number of patients; CRSwNP: Chronic Rhinosinusitis with polyps; CRSsNP: Chronic Rhinosinusitis without polyps 
Of the 19 patients who underwent surgery with the indication of mucocele, seven had ethmoidal, five had frontoethmoidal, four had sphenoidal, two had frontal, and one had maxillary mucocele, and one patient underwent an orbital decompression procedure for concomitant orbital mucocele.

Of the 34 patients who underwent surgery with the indication of fungal sinusitis, 31 had fungus ball, and three had an appearance of allergic fungal sinusitis.

We found that the number of patients who underwent surgery with the indication of fungal sinusitis was six $(0.5 \%)$ in the first 14-year period, and this number increased to $34(3.5 \%)$ in the last 11-year period.

\section{Discussion}

In this study which evaluated the change in the indications of ESS, we found an upward trend in the years 1994 through 2001, a plateau 2001 through 2004, and an upward trend 2004 through 2011, and a decrease in the number of CRSwNP patients in the years from 2011 through 2018 in parallel with the decrease in the total number of patients who underwent surgery. When the initial 14-year period and the following 11-year period were compared, the changes in $\mathrm{CRSwNP}$ indication were found to have significantly increased.

According to the EPOS 2012 (6), rhinosinusitis with $(\mathrm{CRSwNP})$ or without (CRSsNP) nasal polyps is defined as

Table 3. Comparisons of indications for endoscopic sinonasal surgery

\begin{tabular}{l|c|c|c|c|c|}
\hline Indication & $\begin{array}{c}\mathbf{1 9 9 4 - 2 0 0 7} \\
\mathbf{N = 1 1 7 3}\end{array}$ & $\begin{array}{c}\text { Ratio } \\
\mathbf{( \% )}\end{array}$ & $\begin{array}{c}\mathbf{2 0 0 8 - 2 0 1 8} \\
\mathbf{N = 9 5 4}\end{array}$ & $\begin{array}{c}\text { Ratio } \\
\mathbf{( \% )}\end{array}$ & $\mathbf{p}^{*}$ \\
\hline CRSwNP & 434 & 36.9 & 488 & 51.1 & $<0.001$ \\
\hline CRSsNP & 511 & 43.6 & 219 & 22.9 & $<0.001$ \\
\hline Other & 228 & 19.4 & 247 & 25.9 & $<0.001$
\end{tabular}

N: Number of patients; CRSwNP: Chronic Rhinosinusitis with polyps; CRSsNP:

Chronic Rhinosinusitis without polyps;

*Values in bold font indicate level was statistically significant inflammation of the nose characterized by two or more symptoms, one of which should be nasal blockage, obstruction, congestion, or nasal discharge (anterior/posterior nasal drip); with or without facial pain/pressure; and/or with or without either reduction in or loss of smell. Symptomatology should be supported by obvious disease evident in either nasal endoscopy or $\mathrm{CT}$ imaging. $\mathrm{CT}$ findings include mucosal changes within the ostiomeatal complex and/or sinuses (7). Nasal polyps frequently occur in association with CRS, and their prevalence increases in the presence of accompanying local or systemic diseases (8).There are several lesions that mimic nasal polyps in terms of endoscopic or radiological appearance. These include benign epithelial papillomas, pleomorphic adenoma, tumors of mesenchymal neurogenic, vascular and muscular structures, granulomatous inflammatory diseases and epithelial and mesenchymal malignant tumors (8).

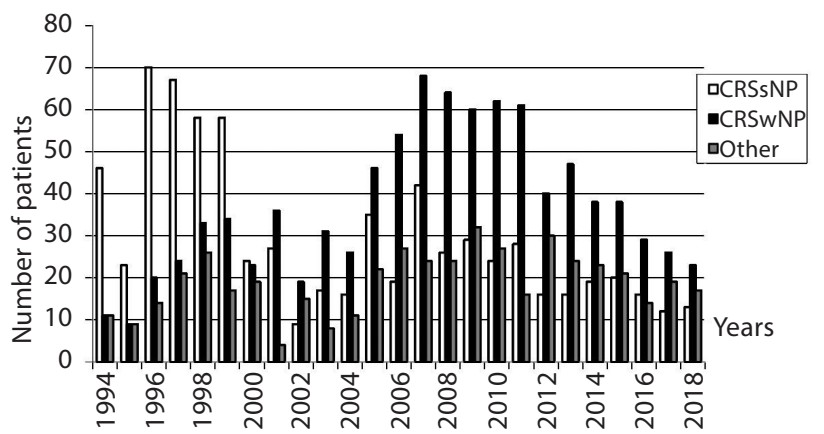

Figure 1. Year-by-year indications for endoscopic sinonasal surgery CRSwNP: Chronic Rhinosinusitis with polyps

CRSsNP: Chronic Rhinosinusitis without polyps

Other: Indications other than chronic rhinosinusitis

Table 4. Indications for endoscopic sinonasal surgery in our institution from 1994 through 2018

\begin{tabular}{|c|c|c|c|c|c|}
\hline Indication & $\begin{array}{c}1994-2007 \\
N=1173\end{array}$ & $\begin{array}{c}\text { Ratio } \\
(\%)\end{array}$ & $\begin{array}{c}2008-2018 \\
N=954\end{array}$ & $\begin{array}{c}\text { Ratio } \\
(\%)\end{array}$ & $\mathrm{p}^{*}$ \\
\hline CRSwNP & 434 & 36.9 & 488 & 51.1 & $<0.001$ \\
\hline CRSsNP & 511 & 43.6 & 219 & 22.9 & $<0.001$ \\
\hline Concha Bullosa & 113 & 9.6 & 57 & 5.9 & 0.002 \\
\hline Nasal/paranasal sinus tumour & 66 & 5.6 & 79 & 8.2 & 0.016 \\
\hline Rhinolith/foreign body & 13 & 1.1 & 27 & 2.8 & 0.004 \\
\hline Mucocele & 11 & 0.9 & 19 & 1.9 & 0.040 \\
\hline Choanal atresia & 7 & 0.6 & 9 & 0.9 & 0.357 \\
\hline Fungal sinusitis & 6 & 0.5 & 34 & 3.5 & $<0.001$ \\
\hline Cerebrospinal fluid leak repair & 5 & 0.4 & 4 & 0.4 & 1.000 \\
\hline Osteoma & 4 & 0.3 & 11 & 1.1 & 0.026 \\
\hline Septal perforation repair & 3 & 0.2 & 7 & 0.7 & 0.123 \\
\hline
\end{tabular}

$\mathrm{N}$ : Number of patients; CRSwNP: Chronic Rhinosinusitis with polyps; CRSsNP: Chronic Rhinosinusitis without polyps

*Values in bold font indicate level was statistically significant 
The option of surgical treatment is considered in patients with CRSsNP and CRSwNP when intensive courses of medical treatment fails or needs to be frequently repeated. The objective of surgical treatment is to eliminate the factors that impair the drainage and the ventilation of paranasal sinuses, to reverse mucosal dysfunction (9).

There is a general agreement that the nose and the sinuses are regarded as a single organ, and all the non-tumoral chronic inflammations are termed as CRS (7). However, a contradictory view has been recently proposed stating that "rhinosinusitis" is not sufficient to express a single organ, non-inflammatory functional pathologies should also be taken into account while planning the treatment (10).

When we evaluated the patients that underwent surgery with an indication of CRSsNP in the initial 14-year period and the following 11-year period, we found that the number of indications had significantly decreased. Bacterial infections were initially believed to play a role in the etiology of CRSsNP and antibiotics were widely used; it was later understood that a serious inflammation accompanied with multifactorial causes, especially eosinophils, where different cytokines played a role led to this clinical picture. The subsequent use of intranasal or systemic steroids as well as anti-inflammatory agents has led to an increase in the effectiveness of medical treatment $(11,12)$. Consequently, we consider that fewer patients may have required surgical treatment.

In a study of 331 patients in whom sinonasal masses were evaluated, non-neoplastic non-infective masses were detected in $74 \%$ of the cases, infective masses were detected in 15\%; neoplastic masses were detected in 11\%; and nasal polyp (ethmoidal + antrochoanal) were detected in $70 \%$ cases (13). When patients with CRSsNP were excluded and sinonasal masses were considered in our study, non-infective masses were found in $72.6 \%$, neoplastic masses in $12.2 \%$, and infective masses were found in $4.6 \%$ of the patients. The rate of the cases with nasal polyps was $66.3 \%$.

Although there is no general agreement on the etiology and pathogenesis of nasal polyps, they are believed to develop as a result of the interaction of various exogenous agents with the nasal mucosa caused by an abnormal host response following a persistent inflammatory process (8). Microorganisms, staphylococcal superantigens, biofilms, fungal infections and immune barrier hypotheses have been focused in pathophysiology, and it is proposed that there is excessive Th2 response and defects in eicosanoid pathway (14).

In the present study, the rate of patients who underwent surgery with an indication of nasal/paranasal sinus tumor in the initial 14 -year period was $5.6 \%$. This rate increased to $8.2 \%$ in the following 11-year period, and it was found that endoscopic approach was used more frequently in the pathologies mentioned under this indication. Sinonasal papillomas require an aggressive treatment due to the high rate of recurrence and the risk of malignant transformation. In a study involving patients who underwent ESS over a period of 12 years, Mackle et al. (15) reported that the endoscopic approach yielded comparable results with the external approach and could be safely used for treating sinonasal papillomas. Yokoi et al. (16) reported a rare case of nasal septal schwannoma with multicentric localization that was successfully treated with ESS.

Paranasal sinus mucoceles are usually benign masses located in the frontoethmoidal region, showing erosion and expansion in the sinus walls characterized with eye complications (17). Mucoceles can be surgically treated. With the development of endoscopes and surgical instruments, marsupialization with ESS has become the preferred method in mucocele treatment today because of advantages such as low morbidity and lack of external scar tissue (17). Similarly, in this study ESS was performed in one patient because of eye complication.

Saprophytic fungi found in the nasal and paranasal sinuses of healthy individuals may occasionally cause specific fungal infections. Fungal infections are examined under two main categories as invasive and noninvasive fungal sinusitis. The invasive form includes acute invasive, chronic invasive and granulomatous fungal rhinosinusitis. The noninvasive form is classified as allergic fungal rhinosinusitis and fungus ball (18). ESS is the gold standard in the treatment of noninvasive fungal rhinosinusitis, and removal of fungal debris from the affected sinuses and restoring the aeration and drainage yield good outcomes (18). In their study evaluating the cases of patients treated with ESS over a period of 15 years, Kim et al. (19) reported that the rate of fungus ball was $2.8 \%$ before 2000 and this rate increased to $8.3 \%$ after 2000. Similarly, Yoon et al. (20) retrospectively analyzed patients and reported that this rate was less than $5 \%$ in patients who underwent surgery prior to 2001 and increased to $13.99 \%$ after 2001 . In our study, this rate was found to be $0.5 \%$ in the years 1994 through 2007; it then increased to $3.5 \%$ in the years 2008 through 2018, and a significant change was noted.

\section{Conclusion}

When the patients treated with ESS over the past 25 years in our center were examined, an upward trend was found in the rate of CRSwNP in the initial 14-year period that was sustained in the following 11-year period, a significant increase was noted in non-CRS cases in the last 11 years; especially in this group, a significant increase was noted in the number of patients with fungal sinusitis consistent with the literature.

Ethics Committee Approval: Ethics committee approval was received for this study from the Clinical Research Ethics Committee of University of Health Sciences Ankara Numune Training and Research Hospital (March 28, 2019; E-19-2638).

Informed Consent: Written informed consent was obtained from the patients who participated in this study.

Peer-review: Externally peer-reviewed. 
Author Contributions: Concept - M.F.K., K.M.Ö., M.Ç., F.C.E., Y.Y., A.T., A.Ü.; Design - M.F.K., K.M.Ö., M.Ö., S.E.K., M.A.Ç.; Supervision - K.M.Ö., M.Ö., M.A.Ç., A.Ü.; Materials - M.F.K., K.M.Ö., M.Ö., M.A.Ç., Y.Y., A.T., A.Ü.; Data Collection and/or Processing - S.E.K., M.A.Ç., M.Ç., F.C.E., Y.Y., A.T., A.Ü.; Analysis and/or Interpretation - M.F.K., M.Ö., S.E.K., M.Ç., F.C.E.; Literature Search - M.F.K., S.E.K., M.Ç., F.C.E., Y.Y., A.T.; Writing - M.F.K.; Critical Reviews - K.M.Ö., M.Ö., A.Ü.

Conflict of Interest: The authors have no conflicts of interest to declare.

Financial Disclosure: The authors declared that this study has received no financial support.

\section{References}

1. Messerklinger W. Endoscopy of the nose. Baltimore: Urban\&Schwartzenberg; 1978.

2. Kennedy DW, Zinreich SJ, Rosenbaum AE, Johns ME. Functional endoscopic sinus surgery: Theory and diagnostic evaluation. Arch Otolaryngol 1985; 111: 576-82. [Crossref]

3. Stammberger H. Endoscopic endonasal surgery- concepts and treatment of recurring rhinosinusitis: I. Anatomic and pathophysiologic considerations, II: Surgical technique. Otolaryngol Head Neck Surg 1986; 94: 143-56. [Crossref]

4. Levine HL. Surgical approaches: Endonasal endoscopic. Levine HL, Clemente MP, editors. Sinus Surgery Endoscopic and Microscopic Approaches. New York: Thieme; 2005.p.148-61. [Crossref]

5. Karakus MF, Ozcan KM, Ozcan M, Yuksel Y, Titiz A, Unal A. Changes in indications for endoscopic sinonasal surgery over 14 years. B-ENT 2008; 4: 221-5.

6. Fokkens WJ, Lund VJ, Mullol J, Bachert C, Alobid I, Baroody F, et al. EPOS 2012: European position paper on rhinosinusitis and nasal polyps 2012. A summary for otorhinolaryngologists. Rhinology 2012; 50: 1-12. [Crossref]

7. Settipane RA, Peters AT, Chandra R. Chronic rhinosinusitis. Am J Rhinol Allergy 2013; 27: 11-5. [Crossref]
8. Settipane RA, Peters AT, Chiu AG. Nasal polyps. Am J Rhinol Allergy 2013; 27: 20-5. [Crossref]

9. Tan BK, Lane AP. Endoscopic sinus surgery in the management of nasal obstruction. Otolaryngol Clin N Am 2009; 42: 227-40. [Crossref]

10. Jankowski R, Nguyen DT, Russel A, Toussaint B, Gallet P, Rumeau C. Chronic nasal dysfunction. Eur Ann Otorhinolaryngol Head Neck Dis 2018; 135: 41-9. [Crossref]

11. Luong A, Marple BF. Sinus surgery: Indications and techniques. Clin Rev Allergy Immunol 2006; 30: 217-22. [Crossref]

12. Bassiouni A, Naidoo Y, Wormald PJ. When FESS fails: The inflammatory load hypothesis in refractory chronic rhinosinusitis. Laryngoscope 2012; 122: 460-6. [Crossref]

13. Nepal A, Chettri ST, Joshi RR, Karki S. Benign sinonasal masses: A clinicopathological and radiological profile. Kathmandu Univ Med J 2013; 41: 4-8. [Crossref]

14. Hsu J, Peters AT. Pathophysiology of chronic rhinosinusitis with nasal polyp. Am J Rhinol Allergy 2011; 25: 285-90. [Crossref]

15. Mackle T, Chambon G, Garrel R, Meieff M, Crampette L. Endoscopic treatment of sinonasal papilloma: A 12 year review. Acta Otolaryngol 2008; 128: 670-4. [Crossref]

16. Yokoi H, Tsutsumi S, Kohno N. Schwannoma of the nasal septum presenting as a multicentric neuronal tumour. B-ENT 2015; 11 : 141-5.

17. Büyüklü F, Çakmak Ö. Ethmoid sinus mucocele with orbital involvement: Report of two cases. Turk Arch Otolaryngol 2009; 47: 174-8.

18. Nicolai P, Lombardi D, Tomenzoli D, Villaret AB, Piccioni M, Mensi M, et al. Fungus ball of the paranasal sinuses: Experience in 160 patients treated with endoscopic surgery. Laryngoscope 2009; 119: 2275-9. [Crossref]

19. Kim JS, So SS, Kwon SH. The increasing incidence of paranasal sinus fungus ball: A retrospective cohort study in two hundred forty-five patients for fifteen years. Clin Otolaryngol 2017; 42: 175-9. [Crossref]

20. Yoon YH, Xu J, Park SK, Heo JH, Kim YM, Rha KS. A retrospective analysis of 538 sinonasal fungus ball cases treated at a single tertiary medical center in Korea (1996-2015). Int Forum Allergy Rhinol 2017; 7: 1070-5. [Crossref] 